\title{
Marantodes pumilum (Blume) Kuntze (Kacip Fatimah) stimulates uterine contraction in rats in post-partum period
}

\author{
Wan Fatein Nabeila Wan Omar, Nelli Giribabu, Kamarulzaman Karim, Naguib Salleh* \\ Department of Physiology, Faculty of Medicine, University of Malaya, 50603, Lembah Pantai, Kuala Lumpur, Malaysia
}

\section{A R T I C L E I N F O}

\section{Keywords:}

Marantodes pumilum leaves

Uterine contraction

Uterotonins

Post-partum

Rats

\begin{abstract}
A B S T R A C T
Ethnopharmacological relevance: Marantodes pumilum (Blume) Kuntze has traditionally been used to firm the uterus after delivery, however scientific evidences behind this claim is still lacking.

Aims of study: To demonstrate Marantodes pumilum leaves aqueous extract (MPE) has an effect on uterine contraction after delivery and to elucidate the molecular mechanisms involved.

Methods: Day-1 post-delivery female rats were given MPE (100, 250 and $500 \mathrm{mg} / \mathrm{kg} /$ day) orally for seven consecutive days. A day after the last treatment (day-8), rats were sacrificed and uteri were harvested and subjected for ex-vivo contraction study using organ bath followed by protein expression and distribution study by Western blotting and immunohistochemistry techniques, respectively. The proteins of interest include calmodulin-CaM, myosin light chain kinase-MLCK, sarcoplasmic reticulum $\mathrm{Ca}^{2+}$-ATPase (SERCA), G-protein $\alpha$ and $\beta$ (G $\alpha$ and G $\beta$ ), inositol-triphosphate 3-kinase (IP3K), oxytocin receptor-OTR, prostaglandin (PGF)2 $\alpha$ receptorPGFR, muscarinic receptor-MAChR and estrogen receptor (ER) isoforms $\alpha$ and $\beta$. Levels of estradiol and progesterone in serum were determined by enzyme-linked immunoassay (ELISA).

Results: Ex-vivo contraction study revealed the force of uterine contraction increased with increasing doses of MPE. In addition, expression of CaM, MLCK, SERCA, G $\alpha, G \beta$, IP3K, OTR, PGF2 $\alpha$, MAChR, Er $\alpha$ and ER $\beta$ in the uterus increased with increasing doses of MPE. Serum analysis indicate that estradiol levels decreased while progesterone levels remained low at day-8 post-partum in rats receiving 250 and $500 \mathrm{mg} / \mathrm{kg} / \mathrm{day} \mathrm{MPE}$.

Conclusions: These findings support the claims that MPE help to firm the uterus and pave the way for its use as a uterotonic agent after delivery.
\end{abstract}

\section{Introduction}

Marantodes pumilum (Blume) Kuntze (M. pumilum) is an indigenous plant of Southeast Asia. Locally known as Kacip Fatimah in Malaysia and Selusoh Fatimah in Indonesia (Giribabu et al., 2018b; Wan Hassan Wan, 2007), M. pumilum has been used by many generations of Southeast Asian women to induce and facilitate delivery and to firm the uterus after delivery where the latter could help to reduce the risk of post-partum haemorrhage (Manda et al., 2014). A study by Teoh et al. (2013) has found that M. pumilum is one of the herb commonly used by the Malaysian women during the post-partum period. Beside its reported benefits on the female reproductive system, M. pumilum leaves has been found to possess other health beneficial effects including antitumour and anti-inflammatory (Karimi et al., 2013), promoting skin collagen synthesis (Chua et al., 2012), protecting skin against photoageing (Choi et al., 2010), preventing post-menopausal osteoporosis (Effendy et al., 2017; Mohd Effendy et al., 2015) and promoting healing of the osteoporotic fracture (Abd Jalil et al., 2012). In addition, other parts of M. pumilum such as roots and stems have also been used as medication, often in the form of decoction (Ibrahim and Jaafar, 2011). Previously, our study has shown that the leaves of M. pumilum contain high levels of phenolic acids, flavanoids and diterpenoid which might contribute to its health beneficial effects (Tan et al., 2019).

Uterine contraction is essential for sperm and embryo transport to and from the Fallopian tubes, respectively (Bulletti et al., 2000; Miller, 2018). In addition, uterine contraction also helps to shed the necrotic endometrium during menstruation and to expulse the foetus and placenta at delivery (Jabbour et al., 2006). In post-delivery period, contraction helps the uterus to involute (Braga Paiano et al., 2019). Uterine contraction can be modulated by many factors such as hormones including oxytocin, estrogen and progesterone (Salleh et al., 2015). Apart from hormone, neurotransmitters such as acetylcholine could also stimulate uterine contraction (Sadraei et al., 2012). Contraction is initiated by binding of the hormone/neurotransmitter ligands on their

\footnotetext{
* Corresponding author.

E-mail addresses: naguibsalleh@um.edu.my, naguib.salleh@gmail.com (N. Salleh).
} 


$\begin{array}{ll}\text { Abbreviations } \\ \text { Ach } & \text { Acetylcholine } \\ \mathrm{BSA} & \text { Bovine serum antigen } \\ \mathrm{CaCl}_{2} & \text { Calcium chloride } \\ \mathrm{CAM} & \text { Cell adhesion molecules } \\ \mathrm{DAB} & \text { Diaminobenzidine } \\ \mathrm{ER} \alpha & \text { Estrogen receptor alpha } \\ \mathrm{ER} \beta & \text { Estrogen receptor beta } \\ \mathrm{FSH} & \text { Follicle stimulating hormone } \\ \mathrm{G} \alpha & \mathrm{G} \text { protein } \alpha \\ \mathrm{G} \beta & \mathrm{G} \text { protein } \beta\end{array}$

\section{Abbreviations}

Ach Acetylcholine

CAM Cell adhesion molecules

DAB Diaminobenzidine

Estrogen receptor beta

$\mathrm{G} \alpha \quad \mathrm{G}$ protein $\alpha$

G $\quad$ G protein $\beta$
HEPES (4-(2-hydroxyethyl)-1-piperazineethanesulfonic acid)

$\mathrm{KCl} \quad$ Potassium chloride

MAChR Muscarinic acetylcholine receptor

$\mathrm{MgSO}_{4} \quad$ Magnesium sulfate

MLCK Myosin light chain kinase

MPE M. pumilum leave aqueous extract

$\mathrm{NaCl}$ Sodium chloride

OTR Oxytocin-R Antibody

PI3K Inositol-1,4,5-trisphosphate 3-Kinase

PVDF Polyvinylidene difluoride

SERCA Sarco(endo)plasmic reticulum calcium-ATPases respective receptors in the myometrium which are coupled to G-protein $\alpha, \beta$ and $\gamma$ (Phaneuf et al., 1993). Activation of G-proteins will lead to production of second messenger including phospholipase C (PLC) (Taylor et al., 1991). Activation of phospholipases will result in production of diacylglycerol and IP3 which triggers $\mathrm{Ca}^{2+}$ released from the sarcoplasmic reticulum (SR) and influx of $\mathrm{Ca}^{2+}$ from extracellular fluid (Taylor et al., 1991). The IP3-mediated $\mathrm{Ca}^{2+}$ release from SR is the major factor that is involve in the opening of the voltage-operated $\mathrm{Ca}^{2+}$ (VOC) channels trigger an action potential (AP) (Wrayzx et al., 2003). Besides, increased global intracellular $\mathrm{Ca}^{2+}$ will lead to formation of $\mathrm{Ca}^{2+}$-calmodulin complex which will cause activation of myosin light chain kinase (MLCK) and phosphorylation of the regulatory myosin light chains (Johnson et al., 1996) and subsequent cross-bridging between actin and myosin (Shojo and Kaneko, 2001). Following completion of contraction, relaxation is achieved partly via removing $\mathrm{Ca}^{2+}$ ions from the cytoplasm into the sarcoplasmic reticulum via SERCA pumps (Noble et al., 2009). The role of SERCA in sequestering the $\mathrm{Ca}^{2+}$ into the sarcoplasmic reticulum has been investigated in pregnant rat myometrium (Shmigol et al., 1999).

Although M. pumilum has been claimed to help firm the uterus after delivery (Teoh et al., 2013), there were no scientific evidence to support this claim. Moreover, the underlying molecular mechanisms are unknown. Therefore, this study was aimed to identify the effect of $M$. Pumilum on uterine contraction post-delivery and to elucidate the molecular mechanisms involved. This study is important as it could justify the use of this herb as a uterotonic agent for women in the post-delivery period, which could help to reduce complication such as post-partum haemorrhage.

\section{Methods}

\subsection{Plant source and extraction}

Fresh leaves of Marantodes pumilum (Blume) Kuntze var alata sp. was obtained from Tapah district in Perak, Malaysia. The plant sample was deposited at Herbarium in Rimba Ilmu, University of Malaya, Kuala Lumpur for identification with assigned herbarium number: KLU49047. The leaves were air-dried and then grounded into powder. Each $400 \mathrm{~g}$ of powdered leaves was soaked in $2 \mathrm{~L}$ distilled water for $48 \mathrm{~h}$. The suspension was filtered and the filtrate was subjected to freeze-drying which yielded $7.36 \% \mathrm{w} / \mathrm{w}$, dry weight basis. The extract was stored at $-20^{\circ} \mathrm{C}$ until use. The stock solution was prepared by dissolving small aliquots of the extract in distilled water.

\subsection{Animal preparation}

Adult female Sprague-Dawley (SD) rats weighing 220-250 g were purchased from local supplier and were housed under standard environmental condition with temperature between $25-30{ }^{\circ} \mathrm{C}$, humidity between $30-70 \%$. Animals had free access to rodent food pellet and tap water ad libitum. All experimental procedures were approved by
Institutional Animal Care and Use Committee, University of Malaya with ethics number 2016-170714/PHYSIO/R/NS.

Female rats at pre-oestrous which was identified by daily vaginal smear following to the method as previously described (Marcondes et al., 2002), were allowed to mate at 1:1 ratio with adult male rat by placing them together in a cage, overnight (Giribabu et al., 2014). The presence of vaginal plug or sperm in the vaginal smear the next morning indicates day 1 pregnancy. The female rats were allowed to pregnant till delivery, usually $21 \pm 2$ days. The presence of pups was designated as day 1 post-delivery (post-partum). The pups were humanely sacrificed while the dams were given oral Marantodes pumilum (Blume) Kuntze leaves extract (MPE) for seven (7) consecutive days. The groupings were as follows:

Group 1: received distilled water only (C)

Group 2: received $100 \mathrm{mg} / \mathrm{kg} /$ day MPE (MPE100)

Group 3: received $250 \mathrm{mg} / \mathrm{kg} /$ day MPE (MPE250)

Group 4: received $500 \mathrm{mg} / \mathrm{kg} /$ day MPE (MPE500)

MPE was orally administered by using $18 \mathrm{G}$ oral-gavage tube. MPE doses were selected based on the previous reported effective dose and at these doses, no adverse effects when observed either in humans or animals (Abdul Kadir et al., 2012a, 2012b; Dianita et al., 2015; Ezumi et al., 2007; Mohd Effendy and Shuid, 2014). Following completion of oral MPE treatment (day 8), post-partum rats were humanely sacrificed by cervical dislocation and uteri were removed and subjected for ex-vivo uterine contraction study. Following completion of the study, uteri were subjected for protein expression and distribution analyses.

\subsection{Ex-vivo uterine contraction study}

Ex-vivo uterine contraction study was performed following the method as previously described Salleh et al. (2015).The mid portion of uterine horn was used. In brief, uteri were mounted vertically in an organ bath pre-filled with Krebs-HEPES buffer solution that contains the following compositions: $154.0 \mathrm{mM} \mathrm{NaCl}, 5.4 \mathrm{mM} \mathrm{KCl}, 2.0 \mathrm{mM}$ $\mathrm{MgSO}_{4}, 2.0 \mathrm{mM} \mathrm{CaCl}_{2}, 8.0 \mathrm{mM}$ D-glucose and $10.0 \mathrm{mM}$ HEPES (Sukwan et al., 2014). The $\mathrm{pH}$ of the solution was adjusted to 7.40, and temperature was maintained at $37^{\circ} \mathrm{C}$. The solution was continuously aerated with $95 \% \mathrm{O}_{2} / 5 \% \mathrm{CO}_{2}$. Each strip of uterine horns was hang under $1 \mathrm{~g}$ resting tension and the force was allowed to equilibrate for $30 \mathrm{~min}$. Buffer solution was replaced every $15 \mathrm{~min}$ by flushing and refilling techniques. Contractile forces were recorded isometrically by using a force transducer connected to a bridge amplifier and then to a PowerLab data acquisition system (ADI Instrument, Australia). After a stable spontaneous contraction was achieved, $1 \times 10^{-2} \mathrm{M}$ acetylcholine (Ach) was added to generate maximum contraction force. The contractile waves were recorded. At the end of the experiment, uteri were patted dry and their wet weight was determined. The force of uterine contraction was taken as the ratio of contraction amplitude to its wet weight (tension/g). 
Table 1

Serum sex-steroid levels and estrogen/progesterone ratio in post-partum rats receiving MPE.

\begin{tabular}{|c|c|c|c|c|}
\hline & $\mathrm{C}$ & MPE100 & MPE250 & MPE500 \\
\hline \multicolumn{5}{|l|}{ Estradiol } \\
\hline Day 1 & $139.9 \pm 7.48$ & $150.7 \pm 5.39$ & $142.75 \pm 4.86$ & $152.5 \pm 7.94$ \\
\hline Day 8 & $170.4 \pm 8.73^{*}$ & $203.78 \pm 9.21^{*}$ & $128.21 \pm 11.85$ & $135.66 \pm 15.45$ \\
\hline \multicolumn{5}{|l|}{ Progesterone } \\
\hline Day 1 & $18.87 \pm 4.56$ & $17.73 \pm 3.19$ & $18.05 \pm 6.91$ & $19.71 \pm 3.88$ \\
\hline Day 8 & $125.12 \pm 6.55^{*}$ & $62.44 \pm 5.82^{*}$ & $16.83 \pm 5.52$ & $18.39 \pm 6.16$ \\
\hline Estrogen/Progesterone ratio (Day 8) & 1.36 & 3.25 & 7.61 & 7.37 \\
\hline
\end{tabular}

Data were expressed as mean \pm SEM from six independent observations. ${ }^{*} \mathrm{p}<0.05$ when compared to Day 1 .

\subsection{Measurement of serum hormone levels}

1-2 $\mathrm{ml}$ of venous blood was collected from rats' tail vein on day 1 of post-partum and prior to sacrificed and was allowed to clot at $4^{\circ} \mathrm{C}$, then centrifuged at $3000 \mathrm{rpm}$ at $4{ }^{\circ} \mathrm{C}$ for $15 \mathrm{~min}$. The serum was carefully pipetted and stored at $-80^{\circ} \mathrm{C}$ and then sent to the division of laboratory medicine, University Malaya Medical Centre for hormone profiles analyses including analysis of estradiol and progesterone by using enzyme-linked immunosorbent assay (ELISA) technique.

\subsection{Protein distribution analyses by immunohistochemistry}

Once harvested, uteri were fixed immediately in $10 \%$ formalin overnight. Prior to processing, uteri were dehydrated through increasing concentrations of ethanol, cleared in xylene and blocked in paraffin wax as previously described (Giribabu et al., 2017). Tissues were then cut into $5 \mu \mathrm{m}$ sections, deparaffinised in xylene and finally rehydrated in reducing concentrations of ethanol. 10\% HistoVT buffer (Nacaai Teque, Japan) was used to retrieve the antigen. For immunohistochemistry, tissue sections were incubated with $3 \% \mathrm{H}_{2} \mathrm{O}_{2}$, then blocked in $5 \%$ bovine serum antigen (BSA) for $1 \mathrm{~h}$ at room temperature. This was followed by incubation in primary antibodies: rabbit polyclonal calmodulin (CaM), estrogen receptor $\alpha(\mathrm{Er} \alpha)$ and estrogen receptor $\beta$ (ER $\beta$ ) (Santa Cruz: sc-5537, sc-7207, sc-8974, respectively) and goat polyclonal myosine light chain kinase (MLCK), SERCA, oxytocin receptor (OTR), prostaglandin-2areceptor (PGF2 $\alpha$ R) and muscarinic receptor (M2) (Santa Cruz: sc-12450, sc-8094, sc-8102, sc33303, sc-7472, respectively). Primary antibody incubation was done in PBS containing 1\% BSA and tween-20 overnight. A day after incubations, sections were rinsed thrice, $5 \mathrm{~min}$ each in PBS, then incubated with IgG-HRP conjugated secondary antibody for $1 \mathrm{~h}$ at room temperature. The proteins were stained dark-brown by immersing in diaminobenzidine (DAB) (Nacalai Tesque, Japan). Sections were then rinsed for $5 \mathrm{~min}$ with deionized water. Hematoxylin was used to counterstain and visualize the nuclei. The slides were dehydrated through increasing concentrations of ethanol and xylene and were covered with a drop of DPX mounting medium. All histological images were viewed under Nikon Eclipse 80i camera attached to a light microscope.

\subsection{Protein quantification by Western blotting}

Immediately following harvesting, uteri were snap frozen in liquid nitrogen and were then stored at $-80^{\circ} \mathrm{C}$. Protein extraction was done by using a PRO-PREP ${ }^{\mathrm{TM}}$ solution (Intron, Korea) as previously described (Giribabu et al., 2018a). In brief, $50 \mu \mathrm{g}$ proteins were mixed with a loading dye, separated in SDS-PAGE and transferred onto a PVDF membrane (BIORAD, USA). The membranes were then blocked with $5 \%$
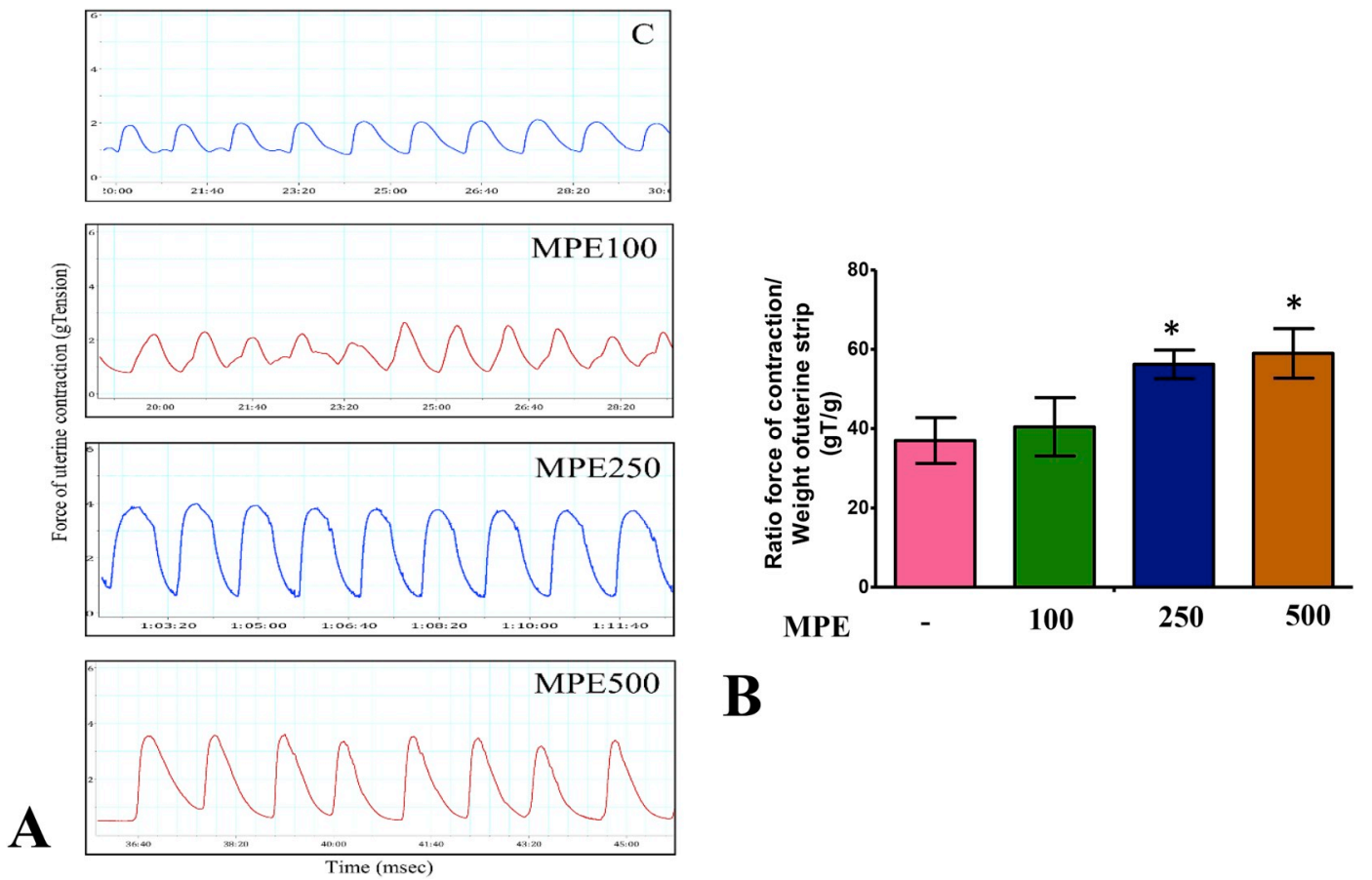

B

Fig. 1. Effect of MPE on uterine contraction ex-vivo. A) A powerlab tracing showing uterine contractile force B) Bar chart showing mean force of uterine contraction with different doses of MPE. Data were expressed as mean \pm SEM from six independent observations. *p $<0.05$ compared to control (without MPE). 


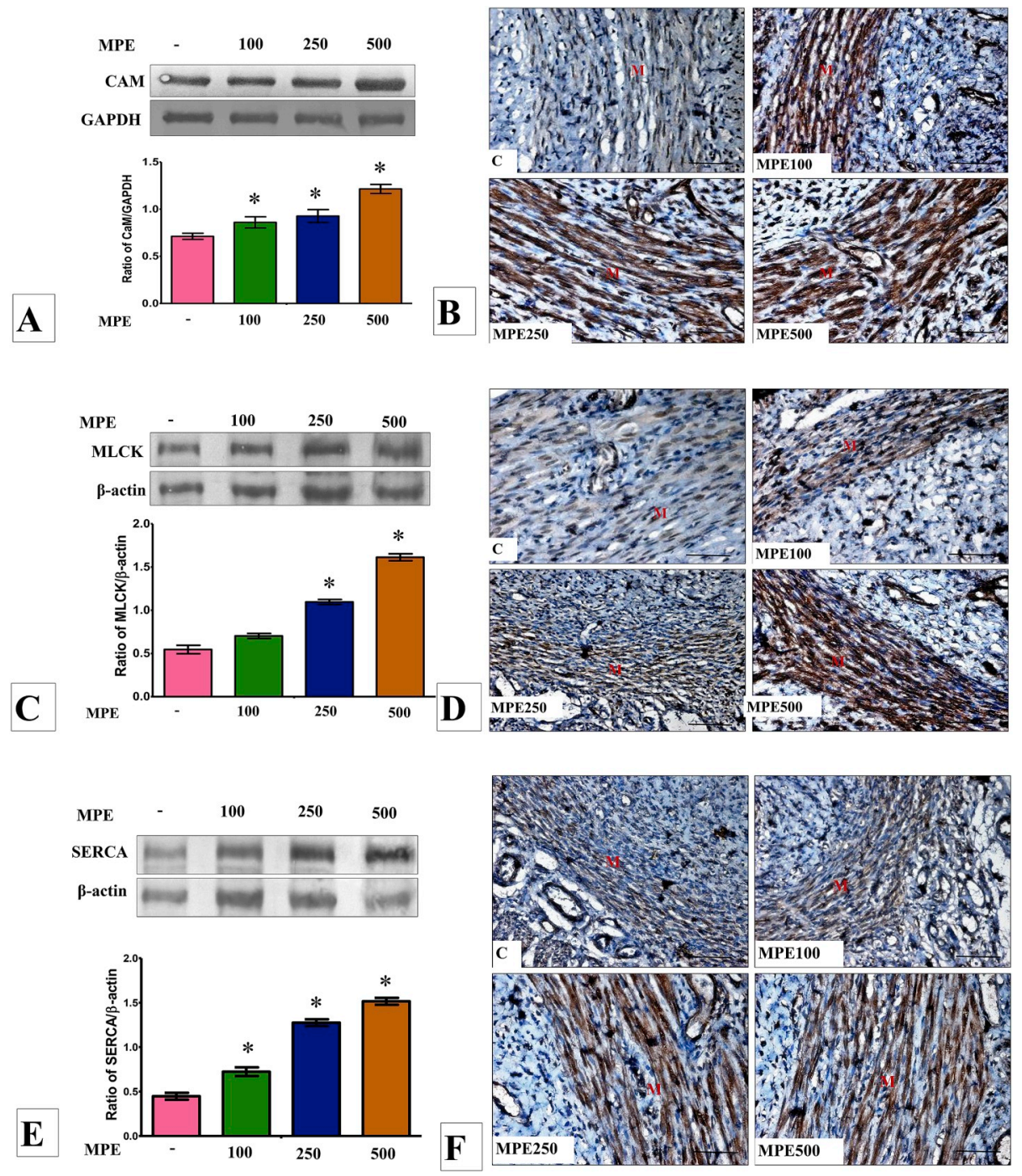

Fig. 2. Representative Western blot images and band intensity analysis of (A) CaM (C) MLCK (E) SERCA and immunohistochemistry images showing (B) CaM (D) MLCK (F) SERCA distribution in the uterus of post-partum rats. C $=$ control, MPE $100=100 \mathrm{mg} / \mathrm{kg} / \mathrm{day}$, MPE $250=250 \mathrm{mg} / \mathrm{kg} / \mathrm{day}$, MPE500 $=500 \mathrm{mg} / \mathrm{kg} /$ day of MPE. $(n=6)$. Images were captured at 20x magnification. Scale bar indicates $100 \mu \mathrm{m}$.

BSA for $60 \mathrm{~min}$ at room temperature and were separately exposed to primary antibodies (as above) with addition of primary antibodies against G-protein $\alpha$ (sc-25413), G-protein $\beta$ (sc-378) and IP3K (sc39064 ) in PBS containing 1\% BSA and tween-20 overnight. Antibodies against $\beta$-Actin (sc-69879), GAPDH (sc-25778) and vinculin (H-300) (sc-5573) were used as loading controls, at concentration of $0.1 \mu \mathrm{g} / \mathrm{ml}$ (1: 1000). The blots were rinsed thrice in PBS-Tween (PBS-T), for $5 \mathrm{~min}$ each. The membranes were then incubated with anti-rabbit and antigoat HRP conjugated secondary antibodies (Santa Cruz, CA, USA) at a concentration of $0.2 \mu \mathrm{g} / \mathrm{ml}(1: 2000)$, for $1 \mathrm{~h}$ and protein bands were detected by using DAB peroxidase staining (DAB kit, Nacalai Tesque). Band images were captured by using UVP BioSpectrum Imaging System (UVP, Canada), and density of each band was quantified by using Image J software (NIH version 1.49j; National Institutes of Health, Bethesda, MD, USA). The ratio of each target protein/loading control was determined and was considered as the expression levels of the targets.

\subsection{Statistical analysis}

Results $(n=6)$ were expressed as mean \pm SEM. Statistical significance was evaluated by one-way analysis of variance (ANOVA) and individual comparison was obtained by using Tukey post-hoc test. $p<0.05$ was considered as significant.

\section{Results}

3.1. Effect of MPE on serum sex-steroid levels and estrogen/progesterone ratio

Serum estradiol levels significantly increased in control group and in group that received MPE100 at day 8 postpartum when compared to day 1 (Table 1). However, in group that received MPE250 and MPE500, no changes in serum estradiol level was observed. In the meantime, there were marked rise in serum progesterone levels in control group and a moderate rise in the group that received MPE100 at day 8 postpartum when compared to day 1 ( $\mathrm{p}<0.05$ ). On the other hand, in the groups that received MPE250 and MPE500, no significant rise in serum progesterone levels were observed. Estrogen/Progesterone ratio were found to be highly elevated in MPE250 and MPE500 groups, approximately 5.5 and 2.3 folds when compared to MPE100 and control groups, respectively.

\subsection{Effects of MPE on uterine contractile force}

The ratio of uterine contractile force to uterine wet weight was approximately 1.48 fold higher in post-partum rats treated with 250 and $500 \mathrm{mg} / \mathrm{kg} /$ day MPE when compared to control $(p<0.05)$ 


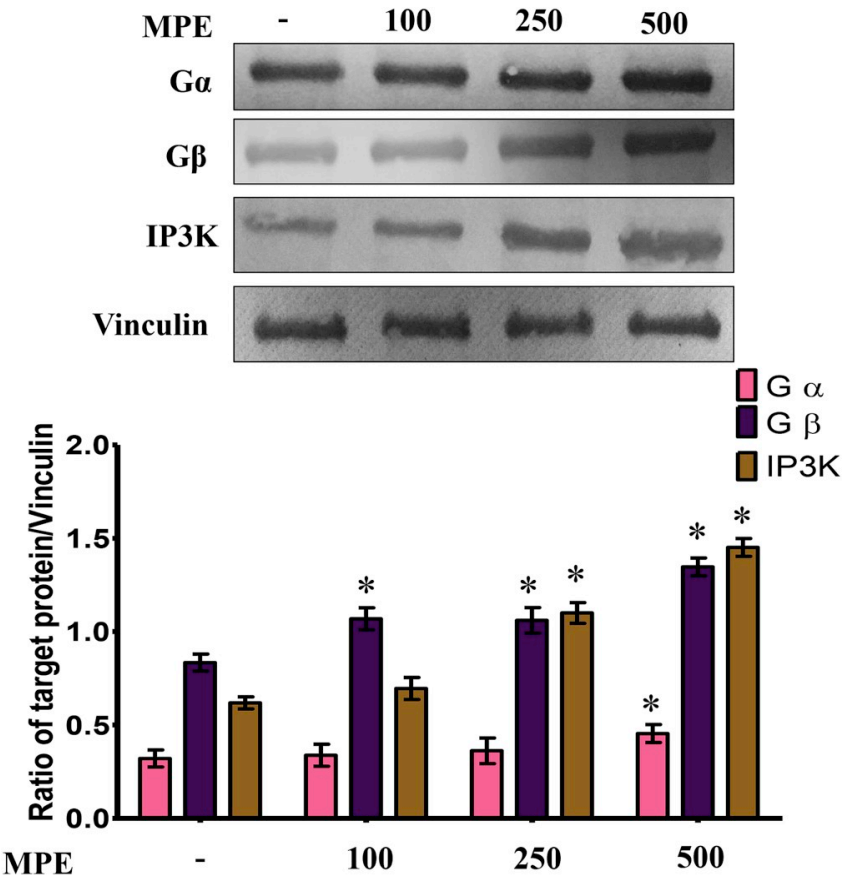

Fig. 3. Representative Western blots images and band intensity analysis of $\mathrm{G} \alpha, \mathrm{G} \beta$ and IP3K in the uterus of post-partum rats. *p $<0.05$ as compared to C. C $=$ control, MPE100 $=100 \mathrm{mg} / \mathrm{kg} /$ day, MPE250 $=250 \mathrm{mg} / \mathrm{kg} /$ day, MPE500 $=500 \mathrm{mg} / \mathrm{kg} /$ day of MPE, $(n=6)$.

(Fig. 1). In the meantime, no significant increase in uterine contractile force was observed following treatment with MPE100 when compared to the control.

\subsection{Effects of MPE on expression and distribution of contractile proteins} (CAM, MLCK and SERCA) in the uterus

\subsubsection{Expression and distribution of CaM}

Expression of CaM increased with increasing doses of MPE. The highest CaM expression was observed in the uterus of MPE500 treated rats (Fig. 2A). In parallel, a relatively higher CaM protein distribution was observed in the uterus in particular in the circular and longitudinal smooth muscles in groups that received $500 \mathrm{mg} / \mathrm{kg} /$ day MPE treatment (Fig. 2B).

\subsubsection{Expression and distribution of $M L C K$}

Expression of MLCK increased with increasing doses of MPE, being highest in group that received MPE500 treatment (Fig. 2C). In parallel, a relatively higher MLCK protein distribution could be seen in the myometrium of MPE500 treated rats as compared to rats that received other treatments (Fig. 2D).

\subsubsection{Expression and distribution of SERCA}

Expression of SERCA in the uterus increased dose-dependently following MPE-treatment, the highest being in MPE500-treated rats (Fig. 2E). In parallel, distribution of SERCA was observed to be relatively higher in the myometrium of MPE500-treated rats when compared to the rats that received MPE100 and MPE250 treatment as well as the control rats (Fig. 2F).

\subsection{Effect of MPE on expression of intracellular signalling proteins in the uterus}

Expression of $\mathrm{G} \alpha$ protein was significantly increased in the uterus of postpartum rats receiving MPE250 and MPE500 treatment $(p<0.05$ when compared to control) (Fig. 3). There was an approximately 4 -fold increase in expression of G $\beta$ protein in the uterus following MPE treatment when compared to control (Fig. 3). In the meantime, expression of IP3K protein in the uterus was also increased following treatment with MPE (Fig. 3).

\subsection{Effect of MPE on expression and distribution of uterotonin receptors (OTR, PGF2R ad MAChR) in the uterus}

\subsubsection{Expression and distribution of OTR}

There was an increased in OTR expression in the uterus following MPE treatment, the highest being in the group that received MPE500 (Fig. 4A). In parallel, a relatively higher OTR distribution was observed in the myometrium in the group that received $500 \mathrm{mg}$ MPE (Fig. 4B).

\subsubsection{Expression and distribution of MAChR}

There was a dose-dependent increase in MAChR expression in the uterus following MPE treatment, the highest being in MPE500 treated group (Fig. 4C). In parallel, a relatively higher MAChR distribution was observed in the myometrium following MPE500 treatment when compared to other groups (Fig. 4D).

\subsubsection{Expression and distribution of PGF2 $\alpha R$}

PGF2 $\alpha$ R expression was highest in the uterus following MPE500 treatment (Fig. 4E). In parallel, a relatively higher PGF2 $\alpha$ R distribution was observed in the myometrium following MPE500 treatment when compared to other groups (Fig. 4F).

\subsection{Effects of MPE on estrogen receptors (ER $\alpha$ and ER $\beta$ ) in the uterus}

\subsubsection{Expression and distribution of ER $\alpha$}

Expression of ER $\alpha$ was highest in the uterus following MPE250 and MPE500 treatments (Fig. 5A). In parallel, a relatively higher ER $\alpha$ distribution was observed in the myometrium following MPE250 and MPE500 treatment when compared to other groups (Fig. 5B).

\subsubsection{Expression and distribution of ERß}

Expression of ER $\beta$ was highest in the uterus following MPE500 treatment (Fig. 5C). In parallel, a relatively higher ER $\beta$ distribution was observed in the myometrium following MPE250 and MPE500 treatments as compared to other groups, consistent with the protein expression findings (Fig. 5D).

\section{Discussion}

To the best of our knowledge, this study is the first to provide evidences supporting the claims that $M$. pumilum helps in inducing uterine contraction in the post-delivery period. Consequently, this effect could help the uterus to adequately firm and assists in reducing the risk of post-partum haemorrhage which is a common complication after delivery (Gallos et al., 2019). We have shown that oral administration of MPE in rats particularly at high dose of $500 \mathrm{mg} / \mathrm{kg}$ /day was able to enhance uterine contraction which imply that MPE has potential to be used as an agent alternative to conventional drug like oxytocin in order to firm the uterus after delivery (Anderson and Etches, 2007).

Apart from the functional findings, our study has unravelled the mechanistic action underlying the uterotonic effect of MPE. There were up-regulation of uterotonin receptors and other contractile-related proteins in the uterus such as CaM and MLCK following MPE treatment. In addition, intracellular signalling proteins i.e. G-protein $\alpha$ and $\beta$ and IP3K were also found to be upregulated by MPE treatment. Additionally, expression of $\mathbf{C a}^{2+}$ transport protein such as SERCA, ER isoforms $\alpha$ and $\beta$ in the uterus were enhanced by MPE treatment. There were several implications for the increased levels of ER in the uterus. Higher ER levels would augment the effect of estrogen on this organ. Studies have shown that ER could act as a transcription factor to induce gene transcription including genes that encodes the receptors for 

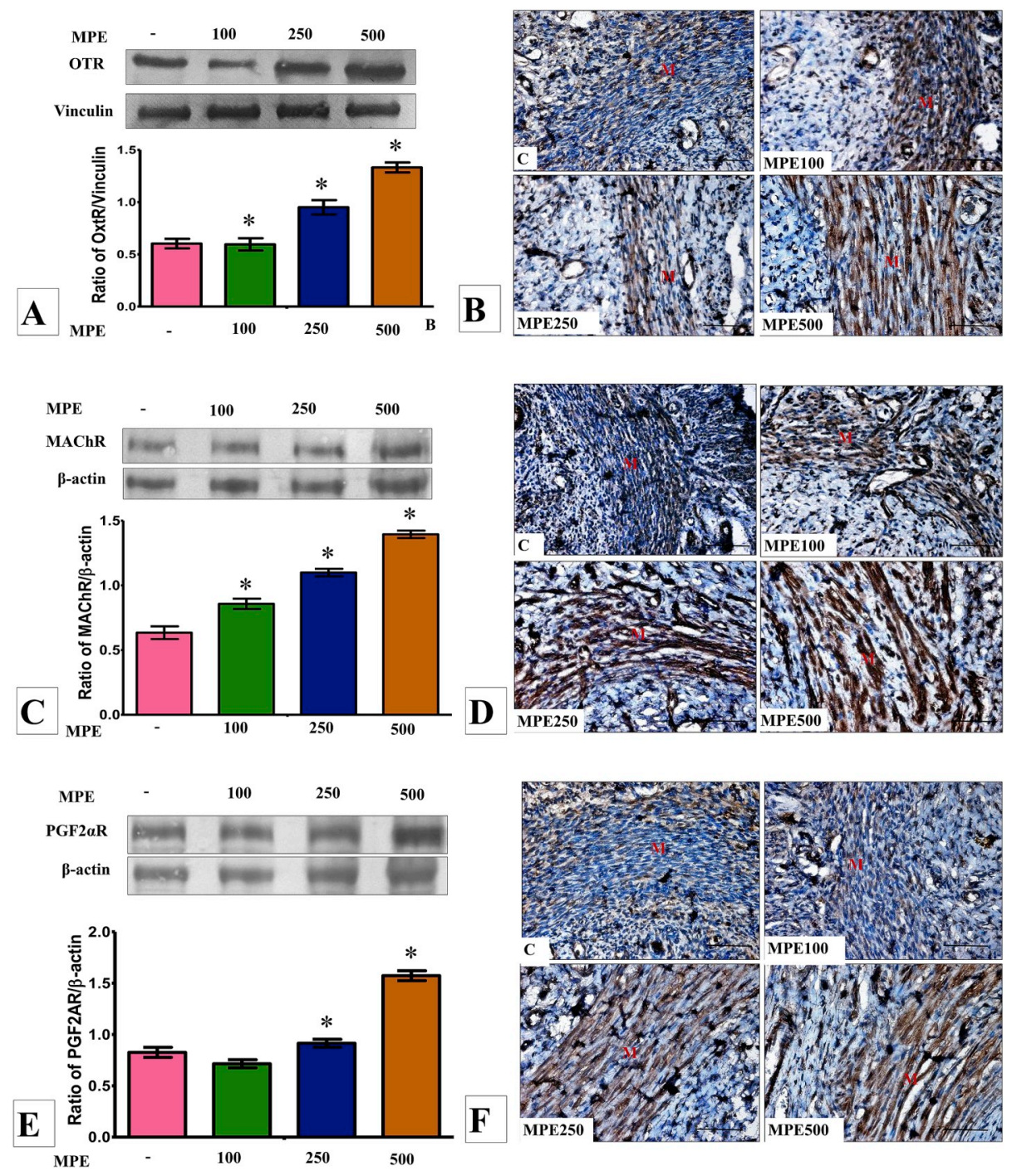

Fig. 4. Western blot image and band intensity analysis of (A) OTR (C) MAChR (E) PGF2 $\alpha$ R and immunohistochemistry images showing (B) OTR (D) MAChR (F) PGF2 $\alpha$ distribution in the myometrium of post-partum rats. C $=$ control, MPE100 $=100 \mathrm{mg} / \mathrm{kg} / \mathrm{day}, \mathrm{MPE} 250=250 \mathrm{mg} / \mathrm{kg} / \mathrm{day}, \mathrm{MPE} 500=500 \mathrm{mg} / \mathrm{kg} /$ day of MPE. $(n=6)$. Images were captured at 20x magnification. Scale bar indicates $100 \mu \mathrm{m}$.

uterotonins (Kuiper et al., 1997; Shughrue et al., 1998). Furthermore, distribution of ER $\alpha$ and ER $\beta$ were localized to the uterine smooth muscle cells which indicate that the target of MPE was the myometrium. It was reported that in the uterus, ERa is the predominant subtype (Pelletier and El-Alfy, 2000). Activation of ER by estrogen would result in up-regulation of uterotonin receptors such as oxytocin, prostaglandin and muscarinic receptors (Gruber and O'Brien, 2011). These receptor levels were found to be markedly increased in the uterus at around the time of delivery under the influence of estrogen (Miyado et al., 2015; Wu et al., 2000). Increased responsiveness of myometrium to estrogen in the post-delivery period is important as falling estrogen levels could cause decreased in the force of uterine contraction (Kota et al., 2013). Estrogen has also been reported to increase oxytocin -related pathway and enhances uterine contractility in rats (An et al., 2013).

Increased number of uterotonin receptors as observed following MPE treatment in the postpartum period would augment the effect of oxytocin, prostaglandins and acetylcholine on the uterus, which subsequently increases the uterine contractile forces. Maintaining high levels of OTR in the myometrium in the post-delivery period is important since OTR levels which increases approximately 200 times at end of gestation secondary to the rise in estrogen, will fall sharply by more than seven folds in the first $24 \mathrm{~h}$ after delivery which would reduce uterine contractility (Gimpl and Fahrenholz, 2001). Since oral MPE treatment up-regulates expression of OTR, therefore there is a likelihood that uterine contraction force would be maintained. In addition to OTR, MAChR levels also increased following MPE treatment in the post-partum period which could help to amplify the ACh action resulting in enhanced force of uterine contraction. It has been reported that expression of MAChR in the uterus greatly increased during parturition which then fell sharply following delivery (). Therefore, maintaining high levels of uterine MAChR could help to sustain uterine contraction in the post-delivery period. Additionally, high expression of PGF $2 \alpha$ R in the myometrium following oral MPE treatment in the postdelivery period would also help to increase the force of uterine contraction in view that prostaglandins has been shown to play an important role in enhancing contraction of the myometrium during labor and in the post-partum period (O'Brien, 1995).

This study has revealed that expression of CaM and MLCK in the post-partum uterus increased following oral MPE treatment where these would directly cause increased in the force of uterine contraction. The upregulation of CaM would enhance formation of $\mathrm{Ca}^{2+}$-calmodulin complex which then activate the MLCK enzymes leading to phosphorylation of myosin light chain, which ultimately enhances the formation of actin-myosin cross-bridges (Hill-Eubanks et al., 2011). Meanwhile, the elevated levels of SERCA in the myometrium following MPE 
MPE
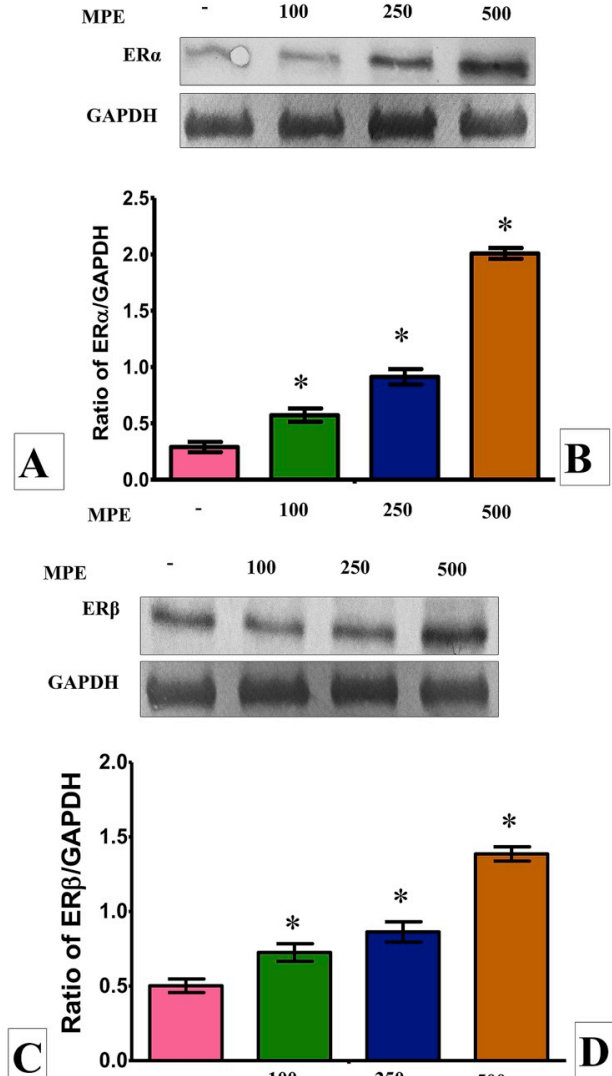

C
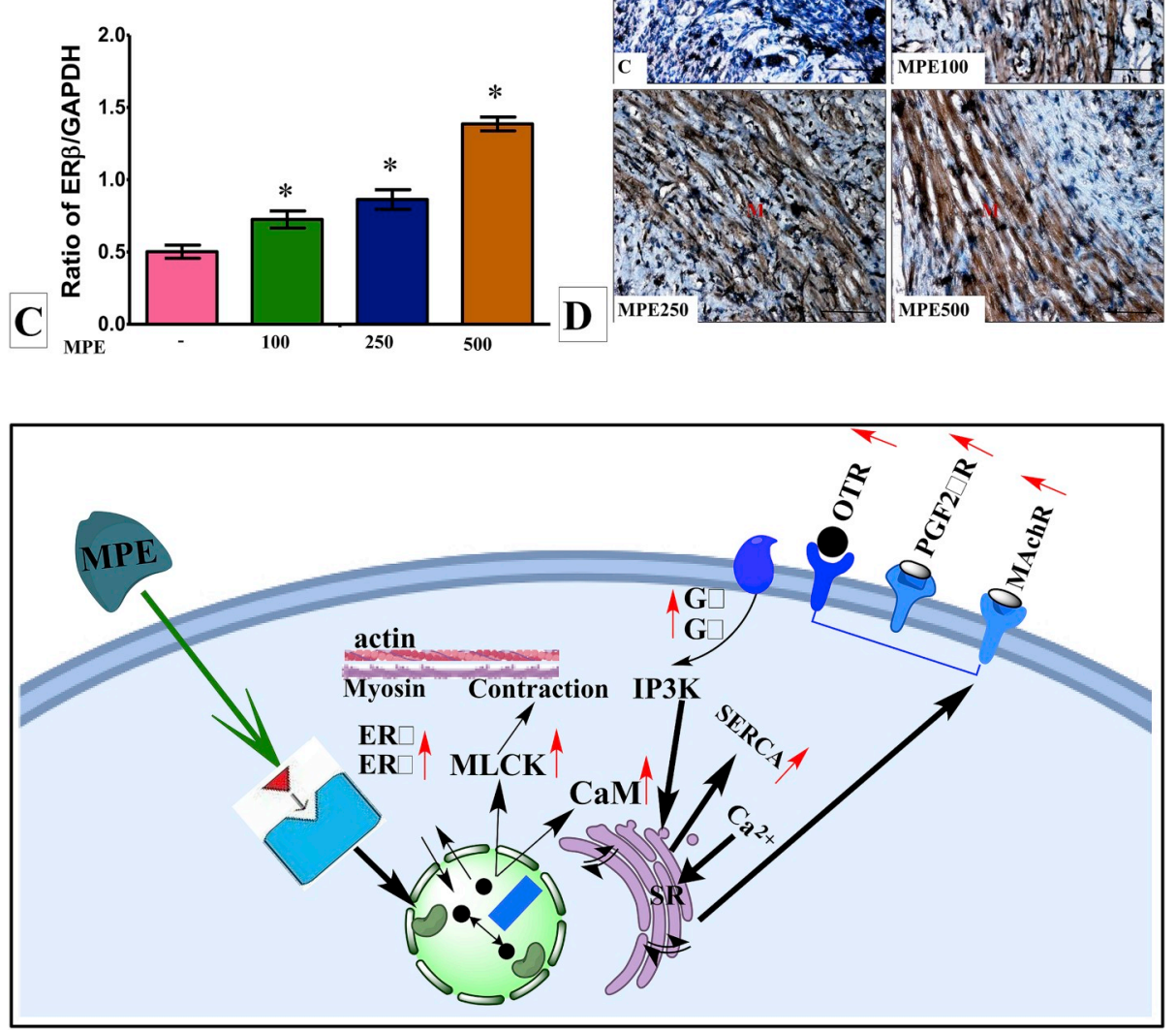

Fig. 5. Western blot image and band intensity analysis of (A) $\operatorname{ER} \alpha$ (C) $\operatorname{ER} \beta$ and immunohistochemistry images showing (B) ER $\alpha$ (D) ER $\beta$ distribution in the uterus of postpartum rats. $\mathrm{C}=$ control, $\mathrm{MPE} 100=100 \mathrm{mg} / \mathrm{kg}$ / day, $\quad$ MPE250 $=250 \mathrm{mg} / \mathrm{kg} /$ day, MPE500 = $500 \mathrm{mg} / \mathrm{kg} /$ day of MPE. $(n=6)$. Images were captured at $20 \mathrm{x}$ magnification. Scale bar indicates $100 \mu \mathrm{m}$.
Fig. 6. Summary of the molecular mechanisms involved underlying the effect of MPE on uterine contraction. MPE bind to ER isoforms in the cytoplasm forming a ligand-receptor complex that translocate into the nucleus leading to transcription of genes that encodes protein including OTR, PGFR, MAChR, CaM, MLCK and SERCA. MPE might also increase G-proteins ( $\mathrm{G} \alpha$ and $\mathrm{G} \beta$ ) and IP3K levels in the myometrium. The resulting increase in IP3K would cause increase in $\mathrm{Ca}^{2+}$ intracellularly via increasing influx of $\mathrm{Ca}^{2+}$ from the sarcoplasmic reticulum (SR) or from extracellular fluid. Increased sarcoplasmic $\mathrm{Ca}^{2+}$ levels would bind to $\mathrm{CaM}$ forming $\mathrm{Ca}^{2+}-\mathrm{CaM}$ complex that activates the MLCK. This would result in phosphorylation of myosin light chain and ultimately cross-bridges between myosin and actin. Contraction is terminated via re-uptake of intracellular $\mathrm{Ca}^{2+}$ into the SR involving SERCA. treatment in post-partum uterus would assist uterine relaxation via reuptake of cytoplasmic $\mathrm{Ca}^{2+}$ into the SR (Berridge, 2008). Increased in IP3K in the uterus following MPE treatment would increase the influx of $\mathrm{Ca}^{2+}$ into the cytoplasm following the binding of IP3K to its specific receptor on the SR. The IP3-mediated $\mathrm{Ca}^{2+}$ release from SR is the major factor that lead to opening of voltage-operated $\mathrm{Ca}^{2+}$ (VOC) channels in the myometrium, leading to the influx of extracellular $\mathbf{C a}^{2+}$ (Wrayzx et al., 2003). In the meantime, increased levels of $G$ proteins $\alpha$ and $\beta$ in the uterus would turn on a cascade of events starting with membrane phospholipase C (PLC) stimulation till production of IP3 which functions are described above. G-proteins activation would also inhibit myosin light chain phosphatase (MLCP) enzyme which is involve in decreasing the force of uterine contraction and induces uterine smooth muscle relaxation (Noda et al., 1995).

The observed uterotonic action of MPE could be attributed to the presence of bioactive compounds in the extract. We recently published a LCMS/MS data analysis which showed that the same extract contains decarboxylated gallic acid (pyrogallol), gallic acid, protocatechuic acid, 4-hydroxybenzoic acid, vanillic acid, myricetin, kaempferol-3-O-rutinoside, kaempferol-7-O-glucoside, 3-3-Di-O-methyellagic acid, apigenin and phytol (Tan et al., 2019). Pyrogallol has been reported to affect prostaglandin synthesis in the rat and human uterus (Kelly and Abel, 1981). 4-hydroxybenzoic acid has been found to possess estrogenlike activity on the uterus however its main action in this organ has not been defined (Koda et al., 2005). Apigenin and myricetin have been reported to possess estrogenic effect on the uterus in inmmature mice (Barlas et al., 2014). In the meantime, estrogenic activity of kaemferol has been widely reported (Breinholt et al., 2000; Stroheker et al., 2002). It is plausible that these compounds might induce up-regulation of the uterine contractile mechanisms (as above) via binding to ER that were 
abundantly presence in the uterus, resulting in a stronger force of uterine contraction.

Meanwhile, serum sex-steroid hormone profiles in the post-partum rats were also found to be altered following MPE treatment. The increased in serum estradiol levels at day-8 post-partum in control rats and in rats receiving $100 \mathrm{mg} / \mathrm{kg} /$ day MPE might be due to the recommencement of the oestrous cycle as there was a report that in rats, ovulation occur as early as $3 \mathrm{~h}$ after parturition (Connor and Davis, 1980). In the meantime, serum progesterone levels in control rats and in rats receiving $100 \mathrm{mg} / \mathrm{kg} /$ day MPE were also found to increase significantly at day-8 post-partum, most probably due to the formation of corpus luteum. On the other hand, serum estradiol levels at day-8 postpartum in rats that received MPE250 and MPE500 have no effect on estradiol biosynthesis in the ovary. High dose MPE of 250 and $500 \mathrm{mg} /$ $\mathrm{kg} /$ day however might suppress progesterone biosynthesis resulting in no rise in serum progesterone levels in these rats at day-8 postpartum. The detail mechanisms involved underlying MPE effect on progesterone levels need to be identified. Suppression of progesterone levels in particular is important since progesterone is known to inhibit myometrial contraction and consequently, this could help to alleviate the uterus from its quiescent state (Soloff et al., 2011). Additionally, we found that there were more than two-fold increase in estrogen/progesterone ratio following MPE250 and MPE500 treatment, which indicate that the uterus was highly contractile. Increased estrogen/progesterone ratio has been found to be parallel with increased contractility of the uterus (Trujillo et al., 2001). Our findings were consistent with the findings in pre and post-menopausal women who were given $200 \mathrm{mg} /$ day $M \mathrm{pu}$ milum extract orally for 12 weeks where there were no significant changes in estradiol levels (George et al., 2014). Similarly, no changes in serum estradiol levels was observed in post-menopausal women consuming $280 \mathrm{mg}$ /day M. pumilum for 6 months period (Abdul Kadir et al., 2012a, 2012b). Despite of these, the effect of oral M. pumilum treatment on serum progesterone levels in humans remain to be identified.

This study has several limitations. The functional study was preliminary, thus further works such as introducing inhibitors targeting at the proteins of interest are needed in order to support the molecular biological analysis. Inhibitors to uterotonin receptors such as atropine (MAChR blocker) (Lochner and Thompson, 2016), atosiban (oxytocin receptor blocker) (Abdullahi et al., 2018) and piprant (PG receptor antagonist) (Kirkby Shaw et al., 2016) could be used to confirm the involvement of these uterotonins in inducing myometrial contraction. In the meantime, thapsigargin, a specific inhibitor for SERCA (Kumar et al., 2019), DY-9836, a specific inhibitor for calmodulin (Wang et al., 2017) and ML-7 and ML-9 (specific MLCK inhibitors) could be used to confirm the involvement of these proteins in regulating myometrial contraction during the post-partum period. Xestospongin B, a competitive inhibitor of IP3K-mediated $\mathrm{Ca}^{2+}$ signalling could be used to confirm the involvement of IP3K in MPE-mediated effect in the uterus in the period post-partum (Jaimovich et al., 2005).

In conclusion, there were several mechanisms which could possibly be involve in MPE-mediated uterine contraction which include upregulation of intracellular proteins that participate in the uterine smooth muscle contraction. In addition, maintaining low progesterone levels could abrogate uterine quiescence thus could increase the intensity of uterine contraction (Astle et al., 2003). Other factors that might also contribute towards increased uterine contraction include increased expression of ER in the myometrium, where these could enhance the estrogen action on the uterus, in particular in causing upregulation of the contraction-associated proteins. Fig. 6 summarizes the possible mechanisms underlying MPE effect in inducing uterine contraction. Based on the above findings, M. pumilum var alata has potential to be used as uterotonic herbal agent to enhance contraction of the uterus after delivery.

\section{Authors' contribution}

WFNWO- performed the studies, write the preliminary manuscript. NG-performed the studies, design the study.

KK- performed the studies.

NS- Design the study, written and final prove-read the manuscript, acquired the grant.

\section{Conflicts of interest}

No conflict of interest reported.

\section{Acknowledgement}

This study was supported by NKEA grant, Ministry Of Agriculture and Agro based Industries, Malaysia, grant number (GA014-2014).

\section{Appendix A. Supplementary data}

Supplementary data to this article can be found online at https:// doi.org/10.1016/j.jep.2019.112175.

\section{References}

Abd Jalil, M.A., Shuid, A.N., Muhammad, N., 2012. Role of medicinal plants and natural products on osteoporotic fracture healing. Evid. Based Complement Altern. Med. 2012, 714512. https://doi.org/10.1155/2012/714512.

Abdul Kadir, A., Nik Hussain, N.H., Wan Bebakar, W.M., Mohd, D.M., Mohammad, W., Zahiruddin, W.M., Hassan, I.I., Shukor, N., Kamaruddin, N.A., Wan Mohamud, W.N., 2012. The Effect of Labisia pumila var. alata on postmenopausal women: a pilot study. Evid. Based Complement Altern. Med. 2012, 216525. https://doi.org/10. $1155 / 2012 / 216525$.

Abdul Kadir, A., Nik Hussain, N.H., Wan Bebakar, W.M., Mohd, D.M., Wan Mohammad, W.M.Z., Hassan, I.I., Shukor, N., Kamaruddin, N.A., Wan Mohamud, W.N., 2012b. The Effect of Labisia Pumila Var. Alata on Postmenopausal Women: A Pilot Study, Evidence-Based Complementary and Alternative Medicine. pp. 1-7.

Abdullahi, P.R., Eskandarian, S., Ghanbari, A., Rashidy-Pour, A., 2018. Oxytocin receptor antagonist atosiban impairs consolidation, but not reconsolidation of contextual fear memory in rats. Brain Res. 1695, 31-36.

An, B.-S., Ahn, H.-J., Kang, H.-S., Jung, E.-M., Yang, H., Hong, E.-J., Jeung, E.-B., 2013. Effects of estrogen and estrogenic compounds, 4-tert-octylphenol, and bisphenol A on the uterine contraction and contraction-associated proteins in rats. Mol. Cell. Endocrinol. 375 (1-2), 27-34.

Anderson, J.M., Etches, D., 2007. Prevention and management of postpartum hemorrhage. Am. Fam. Physician 75 (6).

Astle, S., Slater, D.M., Thornton, S., 2003. The involvement of progesterone in the onset of human labour. Eur. J. Obstet. Gynecol. Reprod. Biol. 108 (2), 177-181.

Barlas, N., Özer, S., Karabulut, G., 2014. The estrogenic effects of apigenin, phloretin and myricetin based on uterotrophic assay in immature Wistar albino rats. Toxicol. Lett. 226 (1), 35-42.

Berridge, M.J., 2008. Smooth muscle cell calcium activation mechanisms. J. Physiol. 586 (Pt 21), 5047-5061.

Braga Paiano, R., Becker Birgel, D., Harry Birgel Junior, E., 2019. Uterine involution and reproductive performance in dairy cows with metabolic diseases. Animals 9 (3), 93.

Breinholt, V., Hossaini, A., Svendsen, G.W., Brouwer, C., Nielsen, S., 2000. Estrogenic activity of flavonoids in mice. The importance of estrogen receptor distribution, metabolism and bioavailability. Food Chem. Toxicol. 38 (7), 555-564.

Bulletti, C., de Ziegler, D., Polli, V., Diotallevi, L., Del Ferro, E., Flamigni, C., 2000. Uterine contractility during the menstrual cycle. Hum. Reprod. (Oxf.) 15 (Suppl. 1), 81-89.

Choi, H.-k., Kim, D.-h., Kim, J.W., Ngadiran, S., Sarmidi, M.R., Park, C.S., 2010. Labisia pumila extract protects skin cells from photoaging caused by UVB irradiation. J. Biosci. Bioeng. 109 (3), 291-296.

Chua, L.S., Lee, S.Y., Abdullah, N., Sarmidi, M.R., 2012. Review on Labisia pumila (Kacip Fatimah): bioactive phytochemicals and skin collagen synthesis promoting herb. Fitoterapia 83 (8), 1322-1335.

Connor, J.R., Davis, H.N., 1980. Postpartum estrus in Norway rats. II. Physiology. Biol. Reprod. 23 (5), 1000-1006.

Dianita, R., Jantan, I., Amran, A., Jalil, J., 2015. Protective effects of Labisia pumila var. alata on biochemical and histopathological alterations of cardiac muscle cells in isoproterenol-induced myocardial infarction rats. Molecules 20 (3), 4746-4763.

Effendy, N.M., Khamis, M.F., Shuid, A.N., 2017. The effects of Labisia pumila extracts on bone microarchitecture of ovariectomized-induced osteoporosis rats: a micro-CT analysis. J. Xray Sci. Technol. 25 (1), 101-112.

Ezumi, M.W., Amrah, S.S., Suhaimi, A., Mohsin, S., 2007. Evaluation of the female reproductive toxicity of aqueous extract of Labisia pumila var. alata in rats. Indian J. Pharmacol. 39 (1), 30.

Gallos, I., Williams, H., Price, M., Pickering, K., Merriel, A., Tobias, A., Lissauer, D., Gee, 
H., Tunçalp, Ö., Gyte, G., 2019. Uterotonic drugs to prevent postpartum haemorrhage: a network meta-analysis. Health Technol. Assess. 23 (9), 1.

George, A., Wilson, D., Abas, A., Evans, M., 2014. Safety and efficacy of a Labisia pumila var alata water extract on sexual well being and lipid profile of pre- and postmenopausal women: a randomized double-blind pilot study. Afr. J. Biotechnol. 13 (6), 768-777.

Gimpl, G., Fahrenholz, F., 2001. The oxytocin receptor system: structure, function, and regulation. Physiol. Rev. 81 (2), 629-683.

Giribabu, N., Karim, K., Kilari, E.K., Kassim, N.M., Salleh, N., 2018a. Anti-inflammatory, antiapoptotic and proproliferative effects of Vitis vinifera seed ethanolic extract in the liver of streptozotocin-Nicotinamide-induced type 2 diabetes in male rats. Can. J. Diabetes 42 (2), 138-149.

Giribabu, N., Karim, K., Kilari, E.K., Salleh, N., 2017. Phyllanthus niruri leaves aqueous extract improves kidney functions, ameliorates kidney oxidative stress, inflammation, fibrosis and apoptosis and enhances kidney cell proliferation in adult male rats with diabetes mellitus. J. Ethnopharmacol. 205, 123-137.

Giribabu, N., Karim, K., Salleh, N., 2018b. Effects of Marantodes pumilum (Kacip Fatimah) on vaginal $\mathrm{pH}$ and expression of vacoular ATPase and carbonic anhydrase in the vagina of sex-steroid deficient female rats. Phytomedicine : Int. J. Phytother. Phytopharm. 49, 95-105.

Giribabu, N., Sainath, S.B., Sreenivasula Reddy, P., 2014. Prenatal di-n-butyl phthalate exposure alters reproductive functions at adulthood in male rats. Environ. Toxicol. 29 (5), 534-544.

Gruber, C.W., O'Brien, M., 2011. Uterotonic plants and their bioactive constituents. Planta Med. 77 (3), 207-220.

Hill-Eubanks, D.C., Werner, M.E., Heppner, T.J., Nelson, M.T., 2011. Calcium signaling in smooth muscle. Cold Spring Harb. Perspect. Biol. 3 (9), a004549.

Ibrahim, M.H., Jaafar, H.Z., 2011. The relationship of nitrogen and C/N ratio with secondary metabolites levels and antioxidant activities in three varieties of Malaysian kacip Fatimah (Labisia pumila Blume). Molecules 16 (7), 5514-5526.

Jabbour, H.N., Kelly, R.W., Fraser, H.M., Critchley, H.O., 2006. Endocrine regulation of menstruation. Endocr. Rev. 27 (1), 17-46.

Jaimovich, E., Mattei, C., Liberona, J.L., Cardenas, C., Estrada, M., Barbier, J., Debitus, C., Laurent, D., Molgó, J., 2005. Xestospongin B, a competitive inhibitor of IP3-mediated $\mathrm{Ca} 2+$ signalling in cultured rat myotubes, isolated myonuclei, and neuroblastoma (NG108-15) cells. FEBS Lett. 579 (10), 2051-2057.

Johnson, J.D., Snyder, C., Walsh, M., Flynn, M., 1996. Effects of myosin light chain kinase and peptides on $\mathrm{Ca} 2+$ exchange with the $\mathrm{N}$-and $\mathrm{C}$-terminal $\mathrm{Ca} 2+$ binding sites of calmodulin. J. Biol. Chem. 271 (2), 761-767.

Karimi, E., Jaafar, H.Z.E., Ahmad, S., 2013. Antifungal, anti-inflammatory and cytotoxicity activities of three varieties of labisia pumila benth: from microwave obtained extracts. BMC Complement Altern. Med. 13 (1), 20.

Kelly, R., Abel, M., 1981. A comparison of the effects of 4-catechol oestrogens and 2pyrogallol oestrogens on prostaglandin synthesis by the rat and human uterus. J. Steroid Biochem. 14 (8), 787-791.

Kirkby Shaw, K., Rausch-Derra, L.C., Rhodes, L., 2016. Grapiprant: an EP 4 prostaglandin receptor antagonist and novel therapy for pain and inflammation. Vet. Med. Sci. 2 (1), 3-9.

Koda, T., Umezu, T., Kamata, R., Morohoshi, K., Ohta, T., Morita, M., 2005. Uterotrophic effects of benzophenone derivatives and a p-hydroxybenzoate used in ultraviolet screens. Environ. Res. 98 (1), 40-45.

Kota, S.K., Gayatri, K., Jammula, S., Kota, S.K., Krishna, S.V., Meher, L.K., Modi, K.D., 2013. Endocrinology of parturition. Indian J. Endocrinol. Metabol. 17 (1), 50-59.

Kuiper, G.G.J.M., Carlsson, B.O., Grandien, K.A.J., Enmark, E., Haggblad, J., Nilsson, S., Gustafsson, J.-a., 1997. Comparison of the ligand binding specificity and transcript tissue distribution of estrogen receptors $\alpha$ and $\beta$. Endocrinology 138 (3), 863-870.

Kumar, N., Khandelwal, N., Kumar, R., Chander, Y., Rawat, K.D., Chaubey, K.K., Sharma, S., Singh, S.V., Riyesh, T., Tripathi, B.N., 2019. Inhibitor of sarco/endoplasmic reticulum calcium-ATPase impairs multiple steps of paramyxovirus replication. Front. Microbiol. 10.

Lochner, M., Thompson, A.J., 2016. The muscarinic antagonists scopolamine and atropine are competitive antagonists at 5-HT3 receptors. Neuropharmacology 108, $220-228$.

Manda, V.K., Dale, O.R., Awortwe, C., Ali, Z., Khan, I.A., Walker, L.A., Khan, S.I., 2014. Evaluation of drug interaction potential of Labisia pumila (Kacip Fatimah) and its constituents. Front. Pharmacol. 5, 178.

Marcondes, F.K., Bianchi, F.J., Tanno, A.P., 2002. Determination of the estrous cycle phases of rats: some helpful considerations. Braz. J. Biol. 62 (4A), 609-614.

Miller, D.J., 2018. Review: the epic journey of sperm through the female reproductive tract. Animal : Int. J. Anim. Biosci. 12 (s1), s110-s120.
Miyado, M., Miyado, K., Katsumi, M., Saito, K., Nakamura, A., Shihara, D., Ogata, T., Fukami, M., 2015. Parturition failure in mice lacking Mamld1. Sci. Rep. 5, 14705.

Mohd Effendy, N., Abdullah, S., Yunoh, M.F., Shuid, A.N., 2015. Time and dose-dependent effects of Labisia pumila on the bone strength of postmenopausal osteoporosis rat model. BMC Complement Altern. Med. 15, 58.

Mohd Effendy, N., Shuid, A.N., 2014. Time and dose-dependent effects of labisia pumila on bone oxidative status of postmenopausal osteoporosis rat model. Nutrients 6 (8), 3288-3302.

Noble, K., Matthew, A., Burdyga, T., Wray, S., 2009. A review of recent insights into the role of the sarcoplasmic reticulum and Ca entry in uterine smooth muscle. Eur. J. Obstet. Gynecol. Reprod. Biol. 144, S11-S19.

Noda, M., Yasuda-Fukazawa, C., Moriishi, K., Kato, T., Okuda, T., Kurokawa, K., Takuwa, Y., 1995. Involvement of rho in GTP $\gamma$ S-induced enhancement of phosphorylation of $20 \mathrm{kDa}$ myosin light chain in vascular smooth muscle cells: inhibition of phosphatase activity. FEBS Lett. 367 (3), 246-250.

O'Brien, W.F., 1995. The role of prostaglandins in labor and delivery. Clin. Perinatol. 22 (4), 973-984.

Pelletier, G., El-Alfy, M., 2000. Immunocytochemical localization of estrogen receptors $\alpha$ and $\beta$ in the human reproductive organs. J. Clin. Endocrinol. Metab. 85 (12), 4835-4840.

Phaneuf, S., Europe-Finner, G., Varney, M., MacKenzie, I., Watson, S., Bernal, A.L., 1993. Oxytocin-stimulated phosphoinositide hydrolysis in human myometrial cells: involvement of pertussis toxin-sensitive and-insensitive G-proteins. J. Endocrinol. 136 (3) 497-NP.

Sadraei, H., Shokoohinia, Y., Sajjadi, S.E., Ghadirian, B., 2012. Antispasmodic effect of osthole and Prangos ferulacea extract on rat uterus smooth muscle motility. Res. Pharm. Sci. 7 (3), 141-149.

Salleh, N., Giribabu, N., Feng, A.O.M., Myint, K., 2015. Bisphenol A, dichlorodiphenyltrichloroethane (DDT) and Vinclozolin affect ex-vivo uterine contraction in rats via uterotonin (prostaglandin F2 $\alpha$, acetylcholine and oxytocin) related pathways. Int. J. Med. Sci. 12 (11), 914-925.

Shmigol, A., Eisner, D., Wray, S., 1999. The role of the sarcoplasmic reticulum as a Ca2+ sink in rat uterine smooth muscle cells. J. Physiol. 520 (1), 153-163.

Shojo, H., Kaneko, Y., 2001. Oxytocin-induced phosphorylation of myosin light chain is mediated by extracellular calcium influx in pregnant rat myometrium. J. Mol. Recognit. 14 (6), 401-405.

Shughrue, P.J., Lane, M.V., Scrimo, P.J., Merchenthaler, I., 1998. Comparative distribution of estrogen receptor- $\alpha(E R-\alpha)$ and $\beta$ (ER- $\beta)$ mRNA in the rat pituitary, gonad, and reproductive tract. Steroids 63 (10), 498-504.

Soloff, M.S., Jeng, Y.-J., Izban, M.G., Sinha, M., Luxon, B.A., Stamnes, S.J., England, S.K., 2011. Effects of progesterone treatment on expression of genes involved in uterine quiescence. Reprod. Sci. 18 (8), 781-797.

Stroheker, T., Pinnert, M., Picard, K., Chagnon, M., Canivenc-Lavier, M., 2002. Estrogenic effects of apigenin, kaempferol and bisphenol A in immature Wistar female rats and in MCF-7 cells. IARC Sci. Publ. 156, 413.

Sukwan, C., Wray, S., Kupittayanant, S., 2014. The effects of Ginseng Java root extract on uterine contractility in nonpregnant rats. Physiological Rep. 2 (12).

Tan, N.A.S., Giribabu, N., Karim, K., Nyamathulla, S., Salleh, N., 2019. Intravaginal treatment with Marantodes pumilum (Kacip Fatimah) ameliorates vaginal atrophy in rats with post-menopausal condition. J. Ethnopharmacol. 236, 9-20.

Taylor, S.J., Chae, H.Z., Rhee, S.G., Exton, J.H., 1991. Activation of the $\beta 1$ isozyme of phospholipase C by a subunits of the Gq class of G proteins. Nature 350 (6318), 516.

Teoh, C.S., M, H.I.A., W, M.W., Ang, S.H., M, Z.N., M, I.N., J, R., 2013. Herbal ingestion during pregnancy and post-partum period is A cause for concern. Med. J. Malays. 68 (2), 157-160.

Trujillo, M., Candenas, L., Cintado, C.G., Magraner, J., Fernandez, J., Martín, J.D., Pinto, F.M., 2001. Hormonal regulation of the contractile response induced by okadaic acid in the rat uterus. J. Pharmacol. Exp. Ther. 296 (3), 841-848.

Wan Hassan Wan, E., 2007. Healing Herbs of Malaysia. Federal Land Development Authority, Kuala Lumpur.

Wang, R., Yin, Y.X., Mahmood, Q., Wang, X.J., Gao, Y.P., Gou, G.J., Ahmed, M.M., Kohji, F., Du, Y.Z., Han, F., 2017. Calmodulin inhibitor ameliorates cognitive dysfunction via inhibiting nitrosative stress and NLRP 3 signaling in mice with bilateral carotid artery stenosis. CNS Neurosci. Ther. 23 (10), 818-826.

Wrayzx, S., Jones, K., Kupittayanant, S., Li, Y., Matthew, A., Monir-Bishty, E., Noble, K., Pierce, S., Quenby, S., Shmygol, A., 2003. Calcium signaling and uterine contractility. J. Soc. Gynecol. Investig. 10 (5), 252-264.

Wu, J.J., Geimonen, E., Andersen, J., 2000. Increased expression of estrogen receptor beta in human uterine smooth muscle at term. Eur. J. Endocrinol. 142 (1), 92-99. 